\title{
Observations on the incidence, aetiology, and pathology of senile osteoporosis
}

\author{
R. A. CALDWELL 1 \\ From the Department of Pathology, University of Sheffield
}

SYNOPSIS Using previously described methods, lumbar vertebral body slabs were investigated radiologically and histologically from 300 unselected cases coming to necropsy. Calcium estimations were also made on the bones of the first 150 cases. High calcium values were mostly encountered in young adults and the calcium values tended to diminish with age, but a wide range of calcium values was still encountered in older subjects. Radiographic density of bone and calcium content tended to be higher in male than in female bone at all ages. The study showed that in subjects aged 50 years or more bone was osteoporotic in $22.5 \%$ of males and in $23.1 \%$ of females. This is a higher incidence than has been previously reported, and is the first accurate study to show equality of incidence in the two sexes.

Although in the relationship between radiographic density and age there was a highly significant overall regression effect, no significant difference was demonstrated between the separate sexes. There was, however, an accelerated falling away in the bone density readings in the fifth and sixth decades which was more pronounced in females. This drop is considered to be connected more with oestrogen deficiency than with deficiency of dietary calcium. Vertebral biconcavity was measured in all cases but was found to be an unreliable sign of osteoporosis.

Osteoporosis, which may be defined as a reduction of calcified bone mass per unit volume of anatomical bone, the remaining bone apparently being normally calcified, occurs in a number of different forms. The commonest variety, called senile osteoporosis, affects women over 45 and men over 55 years of age (Ball, 1960 ) in the absence of obvious aetiological factors such as Cushing's syndrome or hyperthyroidism.

It seems to be generally agreed that in this type of osteoporosis the spine is affected earliest and most severely, followed by the pelvis, then the peripheral limb bones, and occasionally even the skull bones. Assessment during life is difficult, and is usually made by clinical radiography of the spine which has inherent inaccuracies, not the least of which is, that before diagnosis is possible the vertebral bodies must already have lost about $50 \%$ of their bone mass (Fusi, 1953). Although a useful assessment may be made during life by histological examination of bone biopsy material (Beck and Nordin, 1960), only a limited field can be studied, and this is a disadvantage, because as will be shown, osteoporosis does not

${ }^{1}$ Present address: Department of Pathology, Princess Alexandra Hospital, Brisbane, Queensland, Australia.

Received for publication 27 April 1962. always occur uniformly even within the same bone.

Authorities agree that senile osteoporosis is a more common condition than is generally suspected, but fairly wide differences of incidence and sex distribution continue to be described. Cooke (1955) reviewed over 800 reported cases and found that females predominated over males in the ratio of $6: 1$. Lawrence (quoted by Ball, 1960) from a clinical radiographic survey of adults over 15 years of age, noted $2.8 \%$ of osteoporotic cases among 576 males and $10.2 \%$ among 616 females, a female to male ratio of approximately $3: 1$. A post-mortem histological study of 275 consecutive necropsied cases reported by Beck and Nordin (1960) showed an incidence of $12 \%$ in males, and $23 \%$ in females, a female to male ratio of $2: 1$.

There is also diversity of opinion concerning the aetiology of senile osteoporosis, although probably the majority of authors accept the theory advanced by Albright, Bloomberg, and Smith (1940), and later amplified by Albright (1947). This states that the osteoporosis is largely due to decreased osteoblastic activity, and thus diminished osteoid formation, resulting from failure of anabolic steroid hormone production in the face of continued 'anti-anabolic' 
adrenal cortical hormone production. Diminished physical activity is also considered to play a part.

However, a review by Henneman and Wallach (1957) of 15 calcium balance studies, and of serial radiographic examinations in 200 cases of senile osteoporosis treated by sex hormones, failed to reveal conclusive evidence of benefit, although the progress of the condition appeared to be arrested. Furthermore, it has been shown in animals that severe dietary calcium deficiency produced osteoporosis (Korenchevsky, 1922; Light and Frey, 1941; Harrison and Fraser, 1960). Nordin (1958, 1960b, 1961) has therefore suggested that the majority of negative calcium balances, which are a feature of many osteoporotic cases, may be due to dietary calcium deficiency rather than to excess of 'antianabolic' steroid hormone. Harrison and Fraser $(1960,1961)$ have gone further and suggested that in their animal experiments calcium deficiency led to the development of secondary hyperparathyroidism, which caused increased bone resorption and thus osteoporosis, but, on the other hand, Nordin (1960a) has stated that in human cases low calcium intakes did not materially affect the plasma calcium level, and he therefore considered that hyperparathyroidism played no part in producing senile osteoporosis.

Clearly, much more information is required if these differences are to be resolved, and more accurate information concerning the prevalence of the condition and its sex incidence would be an important step. In a preliminary communication Caldwell and Collins (1961) described a rapid and accurate radiographic method for assessing the degree of spinal osteoporosis after death. Some results in a series of 100 necropsies were then presented but a further 200 cases have now been studied, and the analysis of the results of the larger series of 300 cases is the basis of this report.

\section{MATERIALS AND METHODS}

The methods employed were as described by Caldwell and Collins (1961). In short, $1 \mathrm{~cm}$. thick, parallel-sided mid-sagittal slabs of lumbar vertebral bodies were obtained in a random series of 300 necropsies at the Sheffield Royal Infirmary. Bones showing obvious tumour infiltration or Paget's disease had to be excluded, but the remainder after formalin fixation were radiographed wet alongside an aluminium step wedge of 1 to 10 units of thickness $(0.3$ to $3.0 \mathrm{~mm}$.), using a constant exposure and development technique. Bone densities of fourth lumbar vertebral slabs were estimated photometrically in terms of step-wedge units. The bone volumes were then measured by water displacement, and the calcium contents of the ash estimated by standard chemical methods.

The assay is expressed as milligrams of calcium per millilitre of anatomical bone.

\section{RESULTS}

The data in 300 cases are here presented and illus $\overrightarrow{\overrightarrow{5}}$ trated. Quantitative results are summarized i Tables I to IV and in Figs. 1 to 4 and 13. Dat relating to individual cases are not given, but were. available for the statistical analysis.

Bone calcium estimations were made in the first 150 cases, which included 87 men and 63 womerp whose ages ranged from 16 months to 88 years (Table I). The overall average calcium content of the fourth lumbar vertebral body was $68 \mathrm{mg}$. Ca peff $\mathrm{ml}$. of bone (range 38 to $110 \mathrm{mg}$. per ml.), but is $75 \%$ of cases calcium values fell within the narrowe range of 52 to $83 \mathrm{mg}$. per $\mathrm{ml}$.

TABLE I

AVERAGE CALCIUM CONTENT OF

MALE AND FEMALE LUMBAR VERTEBRAL BODIES IN DIFFERENT AGE GROUPS

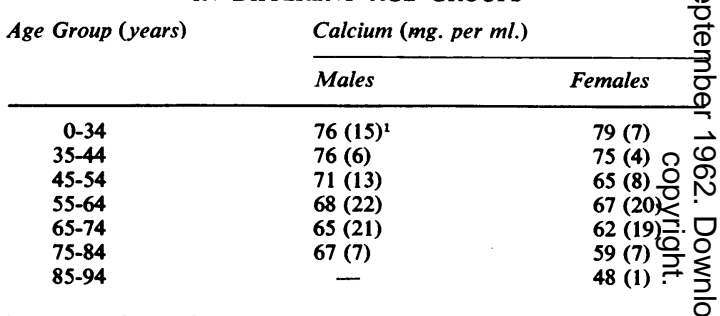

${ }^{1}$ Num'er of cases in each group appended in brackets (150 cases)

Higher calcium values were observed in younge $\overrightarrow{\overrightarrow{0}}$ persons. Thus the three most heavily calcifie vertebrae with 110,102 , and $101 \mathrm{mg}$. Ca per me respectively were from males aged 16 months, 3 ; and 25 years of age, and one with $99 \mathrm{mg}$. Ca was from a woman aged 29 years.

Males tended to have more calcium in a uni volume of vertebral bone than females. The average in 87 male cases was $70 \mathrm{mg}$. Ca per ml. (range 38 to $110)$ and in 63 female cases the average was $66 \mathrm{~ms}$ $\mathrm{Ca}$ per $\mathrm{ml}$. (range 45 to 99 ).

Even when allowance is made for the greater pros portion of young men than of young women in the series the lower calcium content of female bones still evident at almost all ages (Table I). Despite the general decline of calcium in the vertebrae with increasing age, a wide range of calcium values was still encountered in the older age groups. A better correlation was achieved between age and radi\& graphic density measured on a ten degree scal Table II shows the average and range of the calcium content of vertebrae manifesting radiographis densities of 4 to 10 step-wedge units, and Table I I shows the averaged results for males and females 
TABLE II

CALCIUM CONTENT OF MALE AND FEMALE LUMBAR VERTEBRAL BODIES GROUPED ACCORDING TO RADIOGRAPHIC DENSITY IN STEP-WEDGE UNITS (150 CASES)

\begin{tabular}{|c|c|c|c|c|c|c|c|}
\hline \multirow{2}{*}{$\begin{array}{l}\text { Radiographic } \\
\text { Density (step- } \\
\text { wedge units) }\end{array}$} & \multicolumn{2}{|c|}{ Calcium (mg./ml.) } & \multirow{2}{*}{$\begin{array}{l}\text { Total No. } \\
\text { of Cases }\end{array}$} & \multicolumn{2}{|l|}{ Male } & \multicolumn{2}{|l|}{ Female } \\
\hline & Average & Range & & $\begin{array}{l}\text { Number of } \\
\text { Cases }\end{array}$ & $\begin{array}{l}\text { Average Age } \\
\text { (years) }\end{array}$ & $\begin{array}{l}\text { Number of } \\
\text { Cases }\end{array}$ & $\begin{array}{l}\text { Average Age } \\
\text { (years) }\end{array}$ \\
\hline 4 & 48 & - & 1 & - & - & 1 & 88 \\
\hline 5 & 52 & $38-67$ & 26 & 13 & 68 & 13 & $69 \cdot 9$ \\
\hline 6 & 61 & $47-76$ & 47 & 28 & $60 \cdot 6$ & 19 & $62 \cdot 0$ \\
\hline 7 & 74 & $60-89$ & 47 & 29 & $51 \cdot 2$ & 18 & $55 \cdot 1$ \\
\hline 8 & 78 & $69-101$ & 20 & 12 & $40 \cdot 3$ & 8 & $51 \cdot 5$ \\
\hline 9 & 92 & $71-110$ & 7 & 3 & $36 \cdot 8$ & 4 & $37 \cdot 5$ \\
\hline \multirow[t]{2}{*}{10} & 95 & $92-97$ & 2 & 2 & $28 \cdot 5$ & - & - \\
\hline & & & 153 & 87 & & 63 & \\
\hline
\end{tabular}

TABLE III

AVERAGED RESULTS OF BONE CALCIUM ESTIMATIONS OF FOURTH LUMBAR VERTEBRAL BODIES IN 150 CASES

Category

\begin{tabular}{llll} 
Males & \multicolumn{2}{c}{ Females } \\
\cline { 1 - 1 } $\begin{array}{l}\text { No. of } \\
\text { Cases }\end{array}$ & $\begin{array}{l}\text { Calcium } \\
\text { (mg. per } \\
\text { ml. })\end{array}$ & $\begin{array}{l}\text { No. of } \\
\text { Cases }\end{array}$ & $\begin{array}{l}\text { Calcium } \\
\text { (mg. per } \\
\text { ml. })\end{array}$ \\
\hline
\end{tabular}

Total cases

Non-osteoporotic cases 74

Osteoporotic cases

$\begin{array}{ll}70 & 63 \\ 73 & 50 \\ 57 & 1\end{array}$

$\begin{array}{ll}63 & 66 \\ 50 & 69 \\ 13 & 51\end{array}$

Overall average, $68 \mathrm{mg}$. per $\mathrm{ml}$.

Average for non-osteoporotic casss, $71 \mathrm{mg}$. per ml.

Approximate lower limit of normal adult bone, $60 \mathrm{mg}$. per $\mathrm{ml}$.

after classification into osteoporotic and nonosteoporotic groups. As with the previous smaller series, there was a statistically highly significant relationship between quantities of calcium and radiographic density. This larger series showed an even greater degree of correlation between these values. Thus an analysis of variance on calcium and step-wedge data for both sexes combined, testing the effects due to common regression, to difference in location of sex means, and to the very small difference in slopes of separate sex regressions again showed no significant difference between the separate slopes, but an $\mathrm{F}$ criterion for difference in location of means was obtained which was significant at the $1 \%$ level in place of the previous $5 \%$ level $(\mathrm{N}=150)$.

It was thus further confirmed that the step-wedge reading can be used to predict the amount of calcium present, provided that sex is taken into account and the appropriate regression used.

Fig. 1 (males) and Fig. 2 (females) show the distribution of calcium quantities in each step-wedge grcup, and the regression of calcium on step-wedge readings with the calculated $95 \%$ confidence limits.

Fig. 3 compares the regression of calcium on density readings in the two sexes.

The significant difference demonstrated in the location of the means was an unexpected finding and will be discussed.

Because the degree of correlation between the radiographic bone density and calcium content was so satisfactory, a further 150 cases were examined by the radiographic method alone, bringing the total number of cases examined by this method to 300 . One hundred and eighty of these cases were males and 120 were females. Table IV shows the average step-wedge readings of vertebrae, and Fig. 4 shows the regression of radiographic density with age in 10-year age groups of men and women.

TABLE IV

AVERAGE RADIOGRAPHIC DENSITY OF LUMBAR VERTEBRAE OF MALE AND FEMALE SUBJECTS ARRANGED IN 10-YEAR AGE GROUPS (300 CASES)

\begin{tabular}{lllll} 
Age & Males & & Females \\
\cline { 2 - 3 } \cline { 5 - 6 } $\begin{array}{l}\text { No. of } \\
\text { Cases }\end{array}$ & $\begin{array}{l}\text { Average Step- } \\
\text { wedge Reading }\end{array}$ & $\begin{array}{l}\text { No. of } \\
\text { Cases }\end{array}$ & $\begin{array}{c}\text { Average Step- } \\
\text { wedge Reading }\end{array}$ \\
\hline
\end{tabular}

\begin{tabular}{rrrrr}
\hline $0-9$ & 3 & 8 & - & - \\
$10-19$ & 9 & 8 & 1 & 8 \\
$20-29$ & 7 & 8 & 6 & 8 \\
$30-39$ & 14 & 7 & 11 & $7 \cdot 7$ \\
$40-49$ & 14 & $8 \cdot 6$ & 11 & $8 \cdot 0$ \\
$50-59$ & 45 & $6 \cdot 9$ & 29 & $7 \cdot 2$ \\
$60-69$ & 53 & $6 \cdot 0$ & 30 & $6 \cdot 1$ \\
$70-79$ & 25 & $6 \cdot 0$ & 27 & $6 \cdot 0$ \\
$80-89$ & 10 & $5 \cdot 4$ & 5 & $5 \cdot 4$
\end{tabular}

Miss H. M. Davies, of the Department of Statistics, once again undertook the analyses and reported as follows:-

'It was noted that the negative product-moment correlations between step-wedge and age were significant and not much influenced by the presence or absence of the other effects, while that of calcium on age with step-wedge held constant was in both cases very small and well below the borderline of significance, implying some relationship between step-wedge reading and age. 
R. A. Caldwell
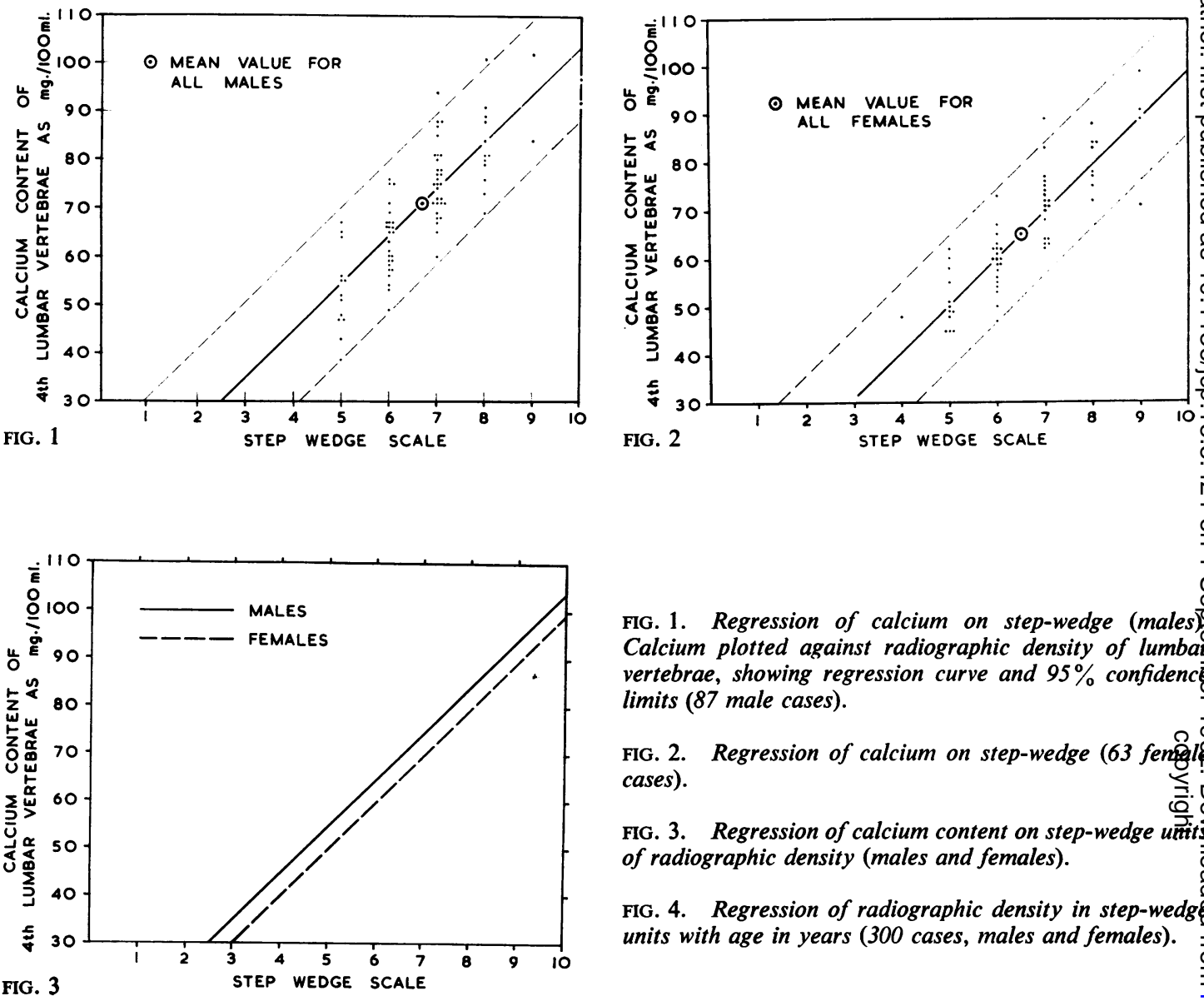

FIG. 1. Regression of calcium on step-wedge (males) Calcium plotted against radiographic density of lumbas vertebrae, showing regression curve and $95 \%$ confidence limits $(87$ male cases).

FIG. 2. Regression of calcium on step-wedge (63 fengी cases).

FIG. 3. Regression of calcium content on step-wedge untits of radiographic density (males and females).

FIG. 4. Regression of radiographic density in step-wedg units with age in years (300 cases, males and females). 
For this reason, an analysis of variance of similar type as before was carried out for the regression of step-wedge on age. This gave a very highly significant value for the combined regression $(F 1,146=61 \cdot 64$ $\mathrm{N}=150$ ) while there was no significant difference for the two sexes between either the separate slopes or the separate locations ( $F$ slightly $<1$ in both cases), implying that there is no sex difference in the effect of age on step-wedge reading, but that there is a marked overall regression effect.

The data for the relationship of step-wedge and age were grouped in decades, and means for each decade were plotted on a graph distinguishing between male and female. These suggested that the relationship was curvilinear rather than linear, and a parabola was fitted to the original data separately for each sex and for the group as a whole. The parabolic regression was found to be a significantly better fit than the straight line (giving F 1,297 = 5.49 which is about equal to the $2 \%$ criterion level of significance). It is clear from the graph that even the curve is not ideal, as there appears to be a sudden drop in the step-wedge readings between the 40- and 50-decades, more than is accounted for by the fitted curve, and more so for the female group than the male'.

Histological sections were made as before in all cases from the third lumbar vertebral slabs, and stained routinely by haematoxylin and eosin, but also for reticulin by Laidlaw's method, because the reticulin stain gives a clearer picture of trabecular structure.

Combined study of the radiographic texture and the histological features of this larger series confirmed that total or patchy porosity in the radiographs and loss of the transverse trabeculae in the sections (Figs. 5 and 6) were constantly associated in bones having a step-wedge density of 5 units or less. Such bones were regarded as showing unequivocal osteoporosis. Sections showing high normal and average normal density are also shown for comparison (Figs. 7 and 8). Rarefaction does not always develop uniformly throughout vertebral bodies but this feature was more easily demonstrated in the radiographs (Fig. 9) than in the sections. As previous authors have noted when reporting on vertebral body sections in osteoporosis, there was a paucity of cells lining the free trabecular borders of either osteoblastic or osteoclastic type. However, in younger individuals aged under 25 years occasional trabeculae showed a lining layer of cuboidal osteoblasts (Fig. 10). These were not seen in older cases, though in them occasional trabeculae were still seen to be lined by a single layer of flattened inactive osteoblasts (Fig. 11). In the sections stained for reticulin, many trabeculae displayed a brush-like fringe (Fig. 12) similar to that described by Ham (1952) at sites of osteoclastic bone resorption, but no osteoclasts were demonstrated in the vicinity of these trabeculae or even elsewhere. It was not found possible to equate the frequency of these 'brush borders' with the bone density results, but an impression was formed that they were less frequently seen in the younger cases, particularly in the four cases under 21 years of age.

It was thus possible to say that 51 of the 300 cases $(17 \%)$ having a step-wedge value of 5 units or less displayed unequivocal osteoporosis. Of these, 30 were males $(16 \cdot 7 \%)$ and 21 were females $(17 \cdot 5 \%)$. Among patients aged 50 or more the incidence was higher, $22.5 \%$ in males and $23.1 \%$ in females.

The average vertebral calcium value for 13 osteoporotic males was $57 \mathrm{mg}$. Ca per ml. compared with $73 \mathrm{mg}$. per $\mathrm{ml}$. for 74 non-osteoporotic male cases. In 13 osteoporotic female cases the average was $51 \mathrm{mg}$. of $\mathrm{Ca}$ per ml. compared with $69 \mathrm{mg}$. of $\mathrm{Ca}$ per $\mathrm{ml}$. for 50 non-osteoporotic female cases. It was not possible to establish an exact level below which a vertebra may be held to be osteoporotic, but in general terms the figure of $60 \mathrm{mg}$. of $\mathrm{Ca}$ per $\mathrm{ml}$. seemed to represent the lower limit of normal for an adult subject (Table III).

The radiographic scale based on a 10-step aluminium wedge gave in effect only eight degrees of bone density, since no bone was encountered so rarefied as to match with the first two steps of the wedge. Two hundred and sixty-seven cases showed densities corresponding with the four step-wedge units 5 to 8 . The 29 bones of greater density showed no pathological variation of either radiographic texture or of histological structure. Of the four examples of bones showing a step-wedge reading of 4 or less, one was from an old lady aged 88 years, who on account of pemphigus had been treated for several weeks before her death with A.C.T.H. and prednisolone, which may have accentuated the osteoporotic process. In no other case were there diseases, or treatments, or other circumstances, which might have caused or accentuated osteoporosis. None of the cases in which osteoporosis was disclosed had complained of symptoms referable to the condition, which was clinically unsuspected.

The period of confinement to bed during the final illness was noted for each case, but could not be correlated with the radiographic bone density, and the nature of the illness was too varied to have a definite bearing on the development of osteoporosis. The youngest female to display spinal osteoporosis was aged 51 years and the youngest male 55 years.

The presence of vertebral biconcavity was measured from the radiographic profile of each fourth lumbar vertebral slab, as the ratio of the least 


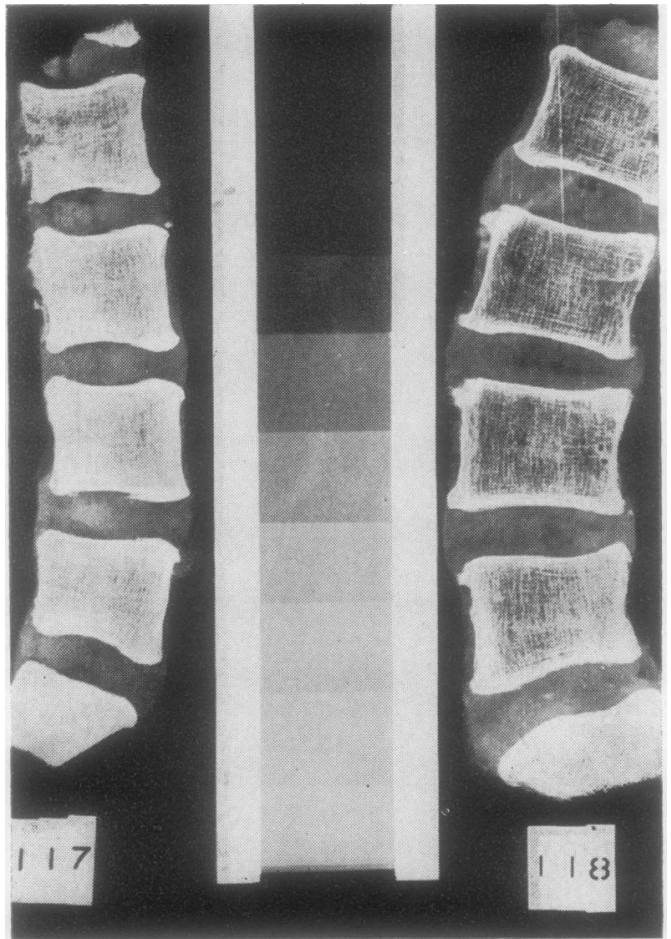

FIG. 5

FIG. 5. Reduction of a radiograph of two vertebral slabs and the aluminium step-wedge.

Specimen 117 (on the left) is from a woman of 70 years who died after thrombosis of the bifurcation of the aorta 86 days after admission to hospital. It shows good normal density. The density of the fourth lumbar vertebra corresponds to that of eight laminae of aluminium (step-wedge 8); the bone contained $88 \mathrm{mg}$. Ca per $\mathrm{ml}$. and the biconcavity index was $84 \%$.

Specimen 118 (on the right) is from a man aged 66 years who died from destruction of the adrenal glands by metastases from carcinoma of the bronchus after only eight days in hospital. It shows osteoporosis and contrasts well with the other specimen. The step-wedge equivalent of the fourth lumbar vertebra was 5 units; the bone contained $55 \mathrm{mg}$. Ca per ml., and the biconcavity index was $90 \%$.

FIG. 6. Lumbar vertebral body (celloidin-paraffin embedded, stained by Laidlaw's reticulin method). This porotic bone showed marked loss of transverse trabeculae, and a radiographic reading of 5 step-wedge units.

FIG. 7. Lumbar vertebral body as Figure 6. This bone, of high normal density, showed numerous transverse trabeculae. The radiographic density was equivalent to 10 stepwedge units (top step of the scale).

FIG. 8. Lumbar vertebral body as Figure 7. This bone, of average normal density, showed a radiographic reading of 7 step-wedge units. Although the trabeculae were in general thin, numerous transverse trabeculae were still present.

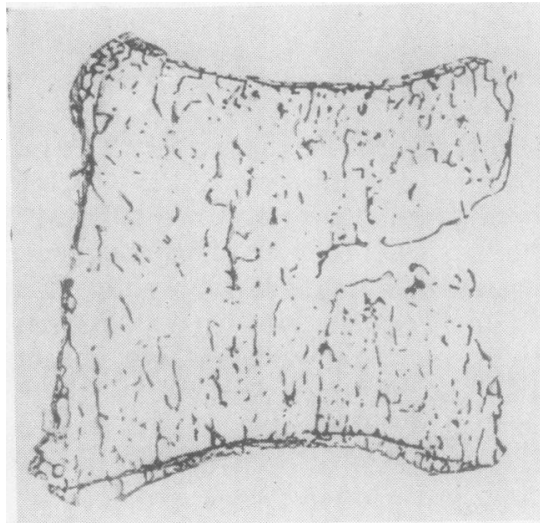

FIG. 6

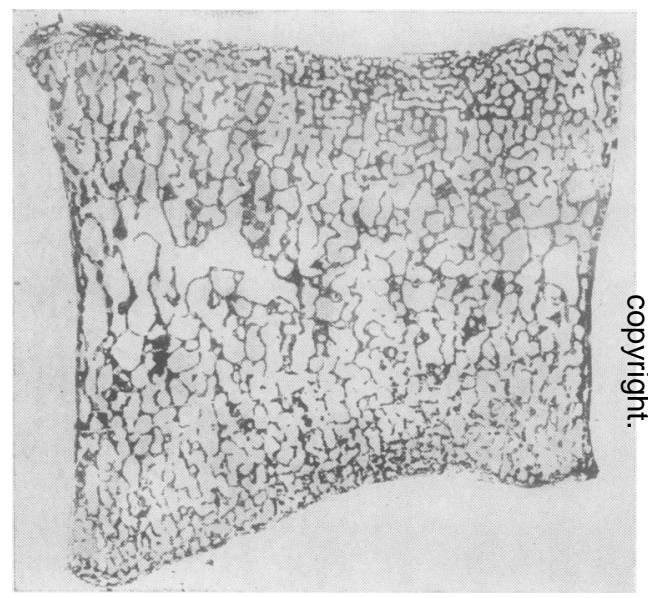

FIG. 7

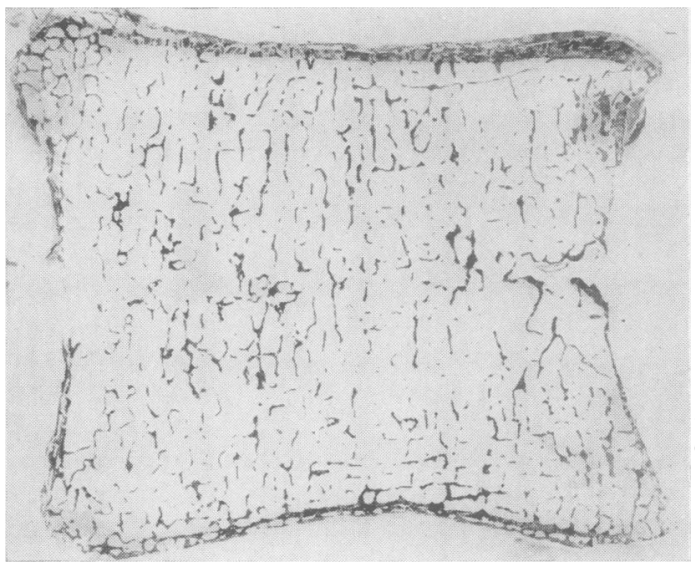

FIG. 8 


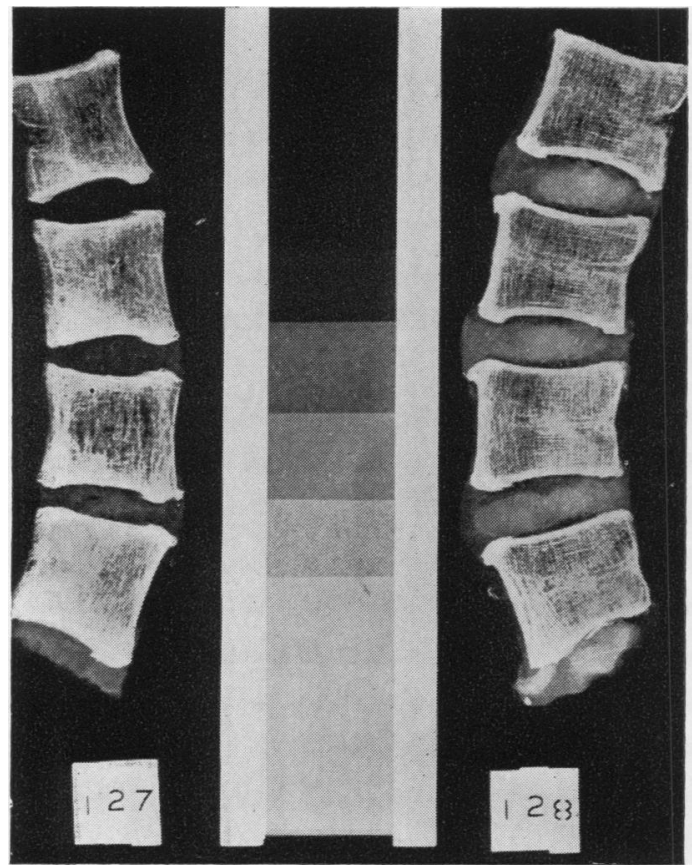

FIG. 9. Reduction of a radiograph of two vertebral slabs and the aluminium step-wedge. Each slab shows commencing osteoporosis which is of patchy distribution. The radiographic density of the fourth lumbar vertebra corresponds to 6 units of the step-wedge scale in specimen 127. In specimen 128 the density of the fourth lumbar vertebra corresponds to 7 units of the scale.

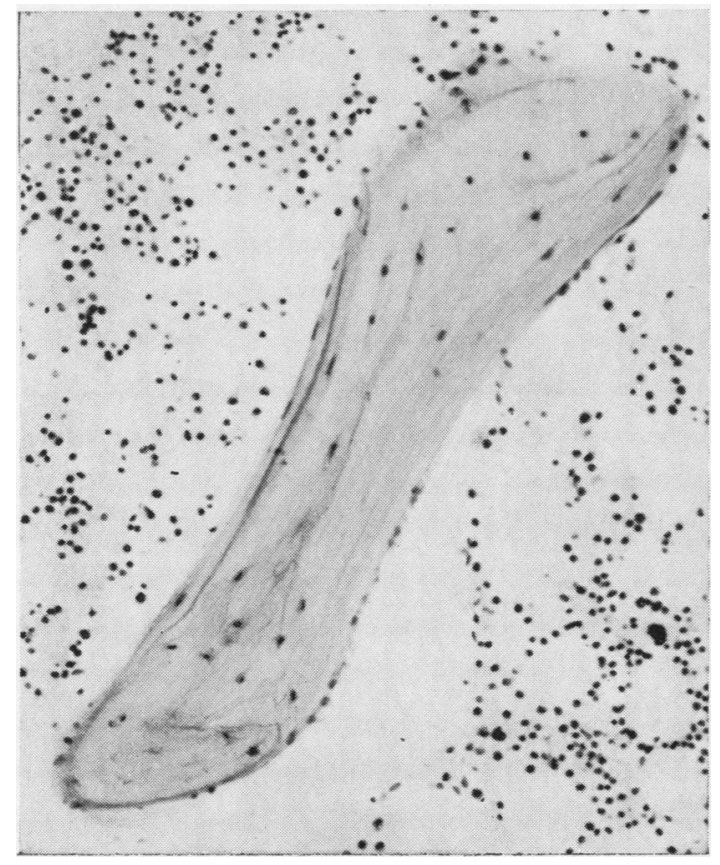

FIG. 10. Section of lumbar vertebra showing cuboidal osteoblasts lining a bone trabecula from a man aged 17 years who died from subarachnoid haemorrhage. The bone radiographic density was equivalent to seven steps of the step-wedge. Haematoxylin and eosin $\times 125$.

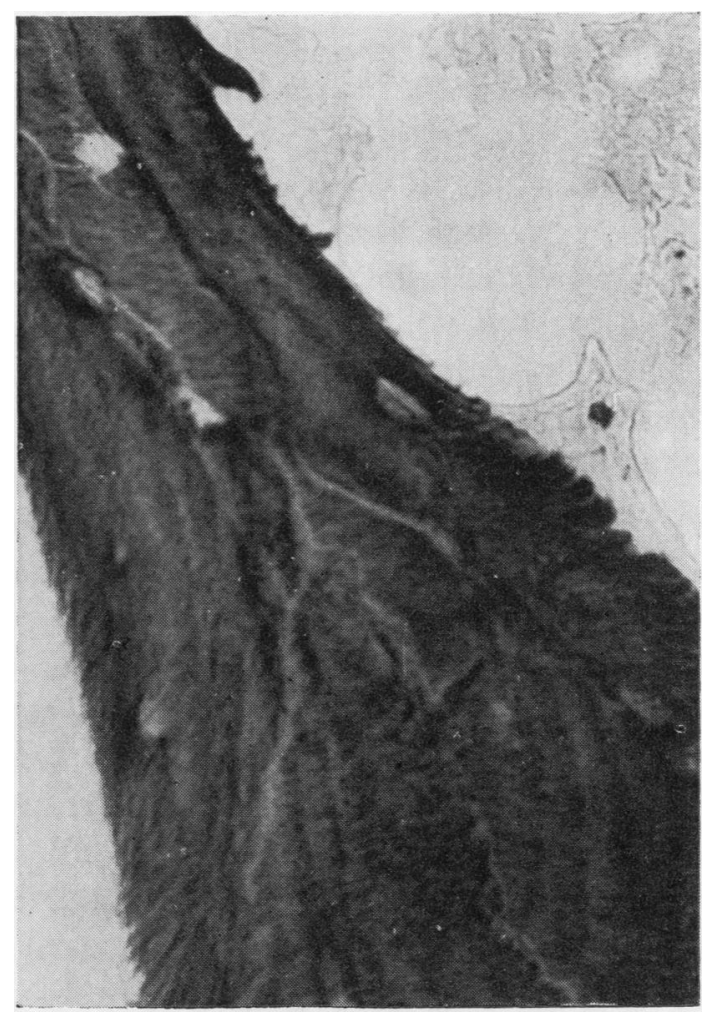

FIG. 12. Histological section of lumbar vertebral body of an adult subject showing a bone trabecula with brush borders. Laidlaw's reticulin stain $\times 500$.

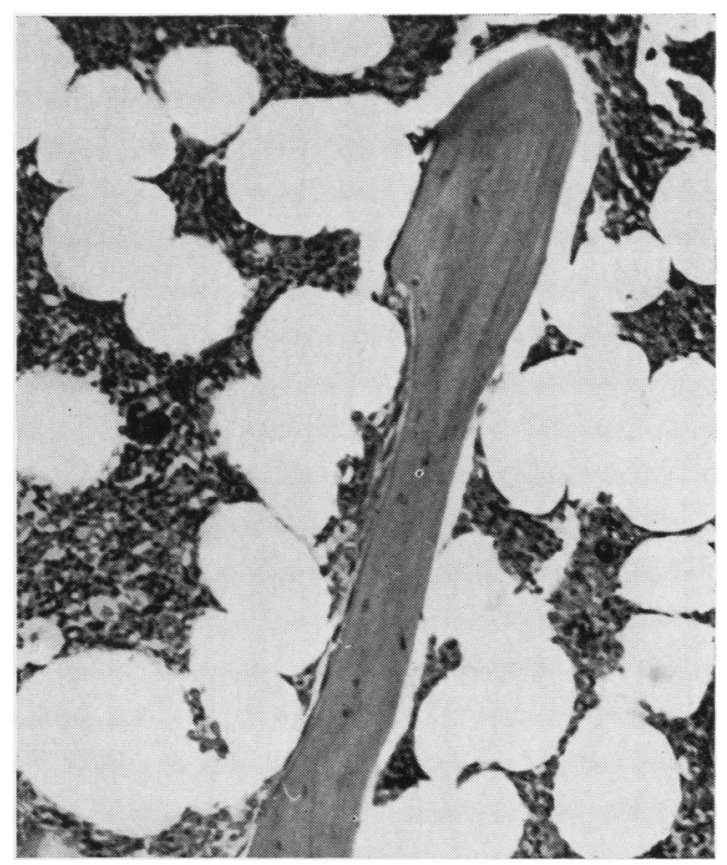

FIG. 11. Section as Figure 10, showing flattened inactive osteoblasts lining a bone trabecula from a wo:nan aged 76 years who died from coronary thrombosis. The bone radiographic density was equivalent to five steps of the step-wedge. Haematoxylin and eosin $\times 125$. 


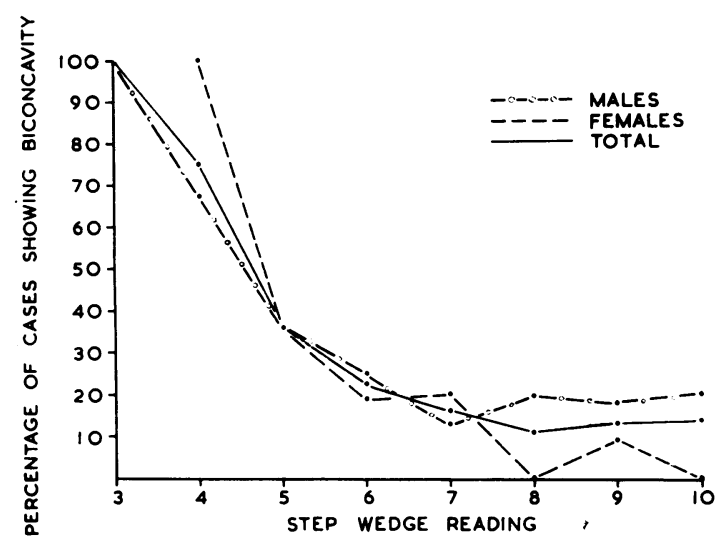

FIG. 13. Graph showing the percentage incidence of fourth lumbar vertebral bodies displaying severe biconcavity in the various grades of radiographic bone density (step-wedge units) in 300 cases.

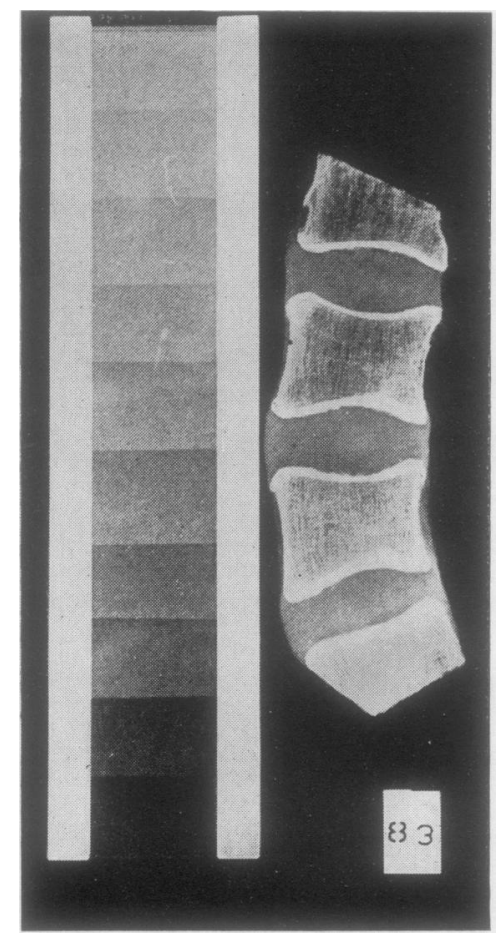

FIG. 14. Reduction of a radiograph of a vertebral slab and the aluminium step-wedge. It is from a man of 75 years who died with cerebral thrombosis after five days in hospital. The biconcavity index was $72 \%$. The bone radiographic density was equivalent to six steps of the stepwedge, and it contained $65 \mathrm{mg}$. Ca per $\mathrm{ml}$. to the greatest vertical depth, which is similar to the method proposed by Barnett and Nordin (1960)․ An index of 80 or less denoted severe biconcavity. $\overrightarrow{\vec{F}}$

Of the 51 osteoporotic cases the average index wast $80 \%$ (range 55 to 93 ), whereas in 29 cases with step-wedge value of 8 or more the average indes. was $86 \%$ (range 73 to 113). The percentage incidence्e of vertebrae showing severe biconcavity in the various grades of step-wedge density is shown iôn Fig. 13. Although the incidence is high in severel$b$ osteoporotic bones, more than $60 \%$ of vertebrae in the osteoporotic range did not show marked biconsu cavity (Fig. 5), and a small proportion of vertebraê of normal (Fig. 14) or even high density did in face show pronounced biconcavity.

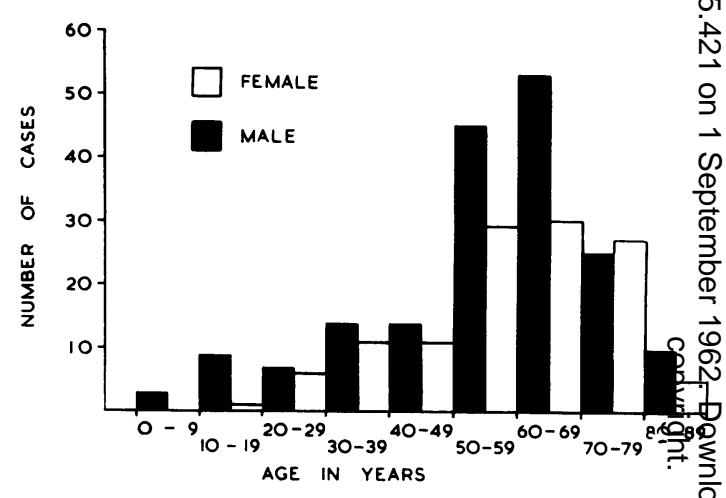

FIG. 15. Histogram showing the composition of the $30 \not$ necropsied cases by age and sex.

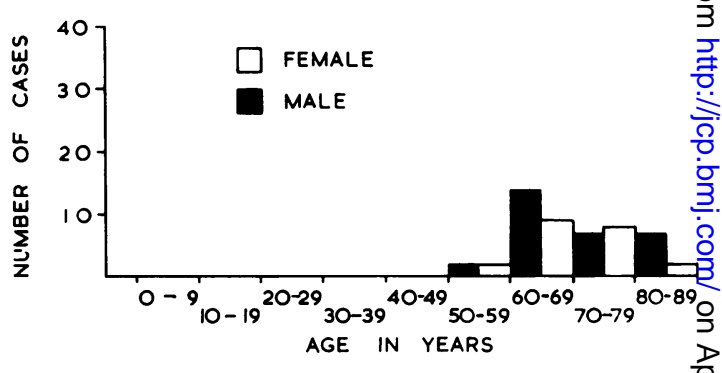

FIG. 16. Histogram showing the composition of the 5 E. cases, adjudged to have osteoporosis, by age and sex. N

Paget's disease is frequently stated to be as pret valent as osteoporosis and in fact Cooke (1955 $55^{\circ}$ considered that it had priority of place. It is notes worthy, therefore, that only one bone sample had te be excluded from this series on account of Paget兽 disease.

The age and sex composition of all the cases in th: series are shown in Fig. 15, and of the cases adjudge $\Phi^{\circ}$ to have osteoporosis in Fig. 16. 


\section{DISCUSSION}

The overall incidence of osteoporosis of $17 \%$ in this series, and the incidence of approximately $23 \%$ in cases of both sexes aged $\mathbf{5 0}$ or more, is, generally speaking, higher than has been previously reported. The majority of previous studies have suggested that there is a predominance of female cases (e.g., Cooke, 1955; Lawrence, quoted by Ball, 1960; Beck and Nordin, 1960) but Urist (1960) stated that although aged men rarely complained of symptoms referable to spinal osteoporosis, the incidence in the two sexes is the same. The results of the present survey accord with his view.

Obviously much will depend on the sample of the population surveyed as well as the suitability and accuracy of the methods employed, but even in a large general hospital necropsy survey some selection of cases is unavoidable, and indeed a greater proportion of young men than of young women is almost inevitable.

Chemical assays on human vertebral bodies expressed as $\mathrm{mg}$. of $\mathrm{Ca}$ per $\mathrm{ml}$. of anatomical bone have not previously been reported, and there are thus no existing standards for comparison. Despite the precision with which the method measures the changes defined as osteoporosis, there was still no distinct point at which it could be said that a bone ceased to be of normal density, and this decision remained to some extent arbitrary. However, one was confident that by taking into account both the radiographic and the histological appearances, only unequivocal cases of osteoporosis were included.

The steady decline with age of bone calcium content (Table I) and of radiographic density (Fig. 4) is clearly seen, as are the somewhat lower calcium values in females in nearly all the age groups. However, even in these age groups the range of calcium results is still wide, and the occasional old person may be found with vertebrae that are highly calcified though histologically normal. The lower calcium values in females may possibly reflect a more delicate trabecular framework in their bones, but the unexpected statistical result showing a significantly lower amount of calcium in female bones than in male bones having the same radiographic density (Fig. 3) is less easy to explain. Calcium has been stated to be responsible for approximately $80 \%$ of radiographic density of bone (Mack, Brown, and Trapp, 1949), which implies that some other radioopaque mineral has partially replaced calcium in the female bones; but further chemical analyses are required to explain this phenomenon.

The significance of the biconcavity results stems from a paper by Black, Ghormley, and Camp in 1941. From a radiographic study of 208 cases of spinal osteoporosis they described vertebral biconcavity in all of 19 in whom the condition was severe. Other authors, e.g., Cooke (1955) and Nassim (1959), have since described biconcavity as a characteristic feature of osteoporosis, and Barnett and Nordin (1960) have even suggested its use as a basis for clinical diagnosis. However, Bohatirchuk (1955), in a radiographic study of 69 elderly subjects, stated that despite the presence of osteoporosis, the vertebrae in subjects who were otherwise normal retained their shape, and similar views have also been expressed by Collins (1949, 1959).

Taking account of these statements, and of the fact that in the present series over $60 \%$ of osteoporotic lumbar vertebrae did not show biconcavity (Fig. 13), whereas a small proportion of vertebrae of normal density did (Fig. 14), it is concluded that vertebral biconcavity is not a reliable radiographic sign of osteoporosis.

Junghanns (1931) was among the first to suggest that porotic changes in the vertebral bones of the elderly were merely part of a more general, normal, and therefore physiological ageing process. Leaving aside the philosophical aspect of this view, the presence in this series of histologically normal bones of high density in elderly subjects shows that such porotic changes are not invariable, and it is therefore appropriate to consider whether this radiographic survey has given any hints about aetiological factors in osteoporosis.

The relationship between step-wedge density and age for the series as a whole showed a highly significant overall regression effect, which is in keeping with Junghann's theory. Because there was no significant difference between the curves for the two sexes (Fig. 4) only one curve is shown. However, the means of the step-wedge readings in each decade are also shown (Fig. 4) for the separate sexes, and these show a pronounced drop in the 40 - and 50-decades, particularly in the female groups. This drop occurred rather too late in life for it to be entirely, or even largely due to the drain of pregnancy and lactation, which Nordin (1960b) considered 'might very well contribute to the development of osteoporosis if the condition were due to calcium deficiency'. It is also of interest in this connexion that, as with the sex hormones, the prolonged administration of calcium salts to patients with senile osteoporosis (Kesson, Morris, and McCutcheon, 1947) had no appreciable effect on the bone radiographic density, and Urist (1960) could detect no connexion between low calcium intakes and osteoporosis in his cases.

The drop in the bone density readings in the present series did however correspond to graphs (Reifenstein, 1957) showing a decline in the production of sex hormones in both sexes. These 
demonstrated a rapid fall in the latter reproductive years, particularly in respect of oestrogenic substances in both sexes, but more pronounced in females. The view that oestrogen deficiency is highly important in the aetiology of senile osteoporosis is of course not new, but conclusive proof has so far been lacking. Because of this, some authorities recommend (e.g., Cooke, 1955; Whedon, 1956) androgen therapy for both sexes, with only small additional doses of oestrogens, and the reason for the administration of androgens has been stated by Meroney, Rubini, Rosch, Austen, Herndon, and Blythe (1959) to be that although oestrogens are known to stimulate osteoblastic activity androgens are believed to be necessary for matrix formation. However, abundant experimental evidence is now available (Suzuki, 1958) to show that although oestrogens stimulate bone formation in birds and mammals, androgens in fact inhibit this action, and personal experiments (1962) have demonstrated that, despite continuous high calcium intake, osteoporosis could be produced in male rats by gonadal sex hormone deficiency and cured by oestradiol administration. Testosterone was not only ineffective but when combined with oestradiol it inhibited the restoration of normal bone density.

The relevance of the oestrogen deficiency theory in the present series may also be seen in the results of the histological examinations. Because oestrogens are known to stimulate osteoblastic proliferation and activity, the finding of plump osteoblasts lining a fair proportion of the trabeculae of young subjects (Fig. 10) and flattened inactive osteoblasts lining a smaller proportion of trabeculae in older subjects (Fig. 11) is consistent with oestrogen deficiency in the older subjects. In view of the infrequency of osteoclasts, and the fact that with increasing age more trabeculae become devoid of an osteoblastic layer, it is relevant to bear in mind Ham's statement (1952) that in the absence of a protective osteoblastic layer bone is probably always undergoing resorption. By simple deduction it would thus appear that within certain limits the fewer the cells the greater will be the unprotected bone surface, and therefore the greater the rate of bone resorption, and this is consistent with the more recent view that an increased rate of resorption is a more conspicuous feature in osteoporosis than a decreased rate of formation (Heaney and Whedon, 1958; Fraser, 1959; Nordin, 1959). Osteoclastic bone resorption is therefore considered not to play nearly such an important role in osteoporosis as it does for instance in osteitis fibrosa due to hyperparathyroidism.

The lack of correlation between the duration of confinement to bed during the final illness and the bone density readings does not support the view
(Albright, 1947) that diminished physical activity is an important ancillary factor, but it does agree withStevenson's finding (1952) that immobilizatio $\overrightarrow{\vec{F}}$ must be rigid to produce osteoporosis, and also with the statement by Wyse and Pattee (1954) that ever in such cases muscular contractions could prevent it appearance.

In conclusion, one may safely say that senile osteoporosis with its attendant liability to deformitye, disability, and fractures is much more common tha $\vec{D}$ is even yet generally realized, no doubt because sơ many of the cases are asymptomatic, and that, ovef the age of 50, it probably occurs just as frequently in men as in women. By the time it can be recognized by the presence of symptoms and confirmed bys routine radiographic methods, the bone changes are well advanced, and, in view of the relative failure of prolonged administration of sex hormones (Henne $\overrightarrow{0}$ man and Wallach, 1957) may in fact be practically irreversible. Because so many authors have reporte $\vec{g}$ that sex-hormone therapy does, however, appear to arrest the progress of the disease, the problem of earlier diagnosis is therefore of great importance but is outside the scope of the present report. Of greate relevance is the evidence indicating that oestrogeb administration without the addition of androgen may well be a more specific type of therapy for bath sexes than any of the other prevailing forms, valude though they may be.

\section{SUMMARY}

Using previously described methods, radiographi $\overrightarrow{\overline{6}}$ and histological examinations of lumbar vertebra body slabs were made in 300 unselected cases coming to necropsy at the Sheffield Royal Infirmary, an calcium estimations were also made on the bones of the first 150 cases. The purpose was to determine accurately the range of variation of calcium conten $\mathrm{E}$. and radiographic density of normal and osteoporotio bones.

Calcium, expressed as milligrams per millilitre of anatomical bone ranged from 38 to $110 \mathrm{mg}$. per $\mathrm{ml}$ but in $75 \%$ of subjects the range was 52 to $83 \mathrm{~m}$ per $\mathrm{ml}$. High calcium values were mostly encountere in young adults, and the calcium per unit volums tended to diminish with age, but a wide range 95 calcium values was still encountered in older sub jects. Although no exact level could be established to distinguish normal from porotic bone, the figure of $60 \mathrm{mg}$. Ca per ml. seemed to represent the approx mate lower limit of normal for adult subjects.

Bone radiographic density varied from 3 to 10 units of a 1 to 10 unit aluminium step-wedge scalg and both radiographic density and calcium conter tended to be higher in male than in female bones 
all ages. Histological examination in every case excluded causes of bone rarefaction other than pure osteoporosis, and confirmed the decision to regard as porotic all bones having a radiographic density equivalent to five units of the step-wedge scale or less.

By these standards, of the 300 cases, 51, including 30 males and 21 females $(17 \%)$, were deemed to have osteoporosis. The youngest male to show osteoporosis was aged 55 years and the youngest female was aged 51 years. Thus among subjects aged 50 years or more, $22.5 \%$ of males and $23.1 \%$ of females were osteoporotic. This is a higher incidence than has previously been reported, and is the first accurate study to show equality of incidence in the two sexes.

The relationship between radiographic density (step-wedge units) and age showed a highly significant overall regression effect, but there was no significant difference for the separate sexes, either between the slopes or the locations. There was, however, an accelerated falling away of the bone density reading in the 40- and 50-decades, which was more pronounced in females. This drop is considered to be much more consistent with oestrogen deficiency than with dietary calcium deficiency, and some of the recent evidence relating to the current practice of androgen administration to cases of senile osteoporosis is discussed.

Vertebral biconcavity was measured in all cases. Severe biconcavity was present in patients with normal bones, and was frequently absent in cases of osteoporosis. Vertebral biconcavity is therefore not a reliable sign of osteoporosis.

I am very grateful to Miss $H$. M. Davies for the statistical analyses. I have also received much help from Mr. G. Colgrave in the collection of the material, from Mr. T. L. Platts in the radiography and photography, and from Mrs. S. Loomes in the preparation of the histological sections.

\section{REFERENCES}

Albright, F. (1947). Ann. intern. Med., 27, 861.

, Bloomberg, E., and Smith, P. H. (1940). Trans. Ass. Amer. Phycns, 55, 298.

Ball, J. (1960). In Recent Advances in Pathology, 7th ed. Edited by C. V. Harrison, p. 293. Churchill, London.

Barnett, E., and Nordin, B. E. C. (1960). Clin. Radiol., 11, 166.

Beck, J. S., and Nordin, B. E. C. (1960). J. Path. Bact., 80, 391.

Black, J. R., Ghormley, R. K., and Camp, J. D. (1941). J. Amer. med. Ass., 117, 2144.

Bohatirchuk, F. (1955). Brit. J. Radiol., 28, 389.

Caldwell, R. A. (1962). Brit. J. exp. Path., 43, 10

C, and Collins, D. H. (1961). J. Bone Jt. Surg., 43B, 346.

Collins, D. H. (1949). The Pathology of Articular and Spinal Diseases. Arnold, London.

(1959). In Modern Trends in Diseases of the Vertebral Column, ed. R. Nassim and H. J. Burrows, p. 101. Butterworth, London.

Cooke, A. M. (1955). Lancet, 1, 877, 929.

Fraser, T. R. (1959). Brit. med. J., 2, 1468.

Fusi, G. (1953). Radiol. clin. (Basel), 22, 123.

Ham, A. W. (1952). J. Bone Jt. Surg., 34A, 701.

Harrison, M., and Fraser, T. R. (1960). J. Endocr., 21, 197.

- (1961). Lancet, 1, 1015.

Heaney, R. P., and Whedon, G. D. (1958). J. clin. Endocr., 18, 1246. Henneman, P. H., and Wallach, S. (1957). Arch. intern. Med., 100, 715.

Junghanns, H. (1931). Langenbecks Arch. klin. Chir., 165, 303.

Kesson, C. M., Morris, N., and McCutcheon, A. (1947). Ann. rheum. Dis., 6, 146.

Korenchevsky, V. (1922). Spec. Rep. Ser. med. Res. Coun. (Lond.), no. 71, p. 18 .

Light, R. F., and Frey, C. N. (1941). Proc. Soc. exp. Biol. (N.Y.), 48, 256.

Mack, P. B., Brown, W. N., and Trapp, H. D. (1949). Amer. J. Roentgenol., 61, 808.

Meroney, W. H., Rubini, M. E., Rosch, P. J., Austen, F. K., Herndon, E. G., Jr., and Blythe, W. B. (1959). Metabolism, 8, 293.

Nassim, R. (1959). In Modern Trends in Diseases of the Vertebral Column, ed. R. Nassim and H. J. Burrows, p. 125. Butterworth, London.

Nordin, B. E. C. (1958). Brit. med. J., 1, 1415.

(1959). Proc. roy. Soc. Med., 52, 351.

(1960a). In Bone as a Tissue, ed. K. Rodahl, J. T. Nicholson, and E. M. Brown, p. 95. McGraw-Hill, New York.

- (1960b). Clin. Orthop., 17, 235. (1961). Lancet, 1, 1011.

Reifenstein, E. C., Jr. (1957). Clin. Orthop., 9, 30.

Stevenson, F. H. (1952). J. Bone Jt. Surg., 34B, 256.

Suzuki, H. K. (1958). Ibid., 40A, 435.

Urist, M. R. (1960). In Bone as a Tissue, ed. K. Rodahl, J. T. Nicholson, and E. M. Brown, p. 18. McGraw-Hill, New York.

Whedon, G. D. (1956). In Hormones and the Ageing Process, Proc. of a Conference, New York, 1955, ed. E. T. Engle and G. Pincus, p. 221. Academic Press, New York.

Wyse, D. M., and Pattee, C. J. (1954). Amer. J. Med., 17, 645. 